\title{
Natur, Religion, Wissenschaft
}

\author{
Beiträge zur Religionsphilosophie Hermann Deusers \\ Hrsg. v. Markus Kleinert u. Heiko Schulz
}

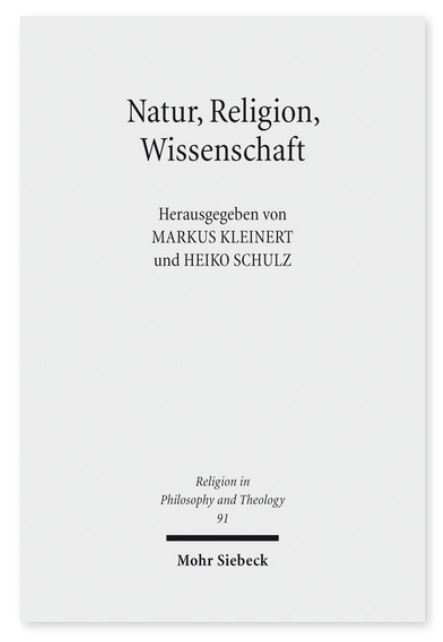

2017. XI, 514 Seiten. RPT 91

ISBN 978-3-16-155013-3 DOI 10.1628/978-3-16-155013-3 eBook PDF 114,00€ ISBN 978-3-16-155012-6 fadengeheftete Broschur 114,00€
Hermann Deuser, international renommierter Theologe, Religionsphilosoph und Fellow am Max-Weber-Kolleg der Universität Erfurt, hat im Februar 2016 seinen 70. Geburtstag gefeiert. Diesem Anlass widmen die Herausgeber mit dem vorliegenden Band eine Sammlung von Aufsätzen, in denen sich namhafte Weggefährten und Kollegen aus dem In- und Ausland zu zentralen Aspekten von Deusers Denken, insbesondere seinen jüngeren und jüngsten Arbeiten zum Verhältnis von (NaturWissenschaft und Theologie bzw. Religion, programmatisch und im Detail äußern. Es handelt sich folglich nicht um eine Festschrift im üblichen Sinne, sondern um eine Anthologie von Originalbeiträgen, die ausschließlich oder zumindest an prominenter Stelle Deusers substantielle Beiträge zur theologischen und religionsphilosophischen Gegenwartsdebatte konstruktiv-kritisch würdigen und weiterdenken. Ein 'donum superadditum' bietet die komprimierte Replik auf die vorangegangenen Beiträge aus Deusers eigener Feder am Ende des Bandes.

\section{Inhaltsübersicht}

Markus Kleinert/Heiko Schulz: Einleitung

\section{Natur}

Melanie Köhlmoos: Naiver Glaube? Schöpfungstheologie in ihrem altorientalischen und alttestamentlichen Kontext - Stefan Alkier: Wunderdenken im Spannungsfeld von Theologie und Kosmologie - Catherina Wenzel: Bildmagie und Distanz in Aby Warburgs 'indianischer Reise'- Svein Aage Christoffersen: »Amor Mundi - warum ist es so schwer die Welt zu lieben?« On the Importance of Metaphysics and Love of the World - Martin Schmuck: Idealismus und Naturalismus. Überlegungen zu den antinaturalistischen Argumenten in Hermann Deusers kosmologischer Theologie - Lukas Ohly: Evolution und Basisvertrauen. Eine phänomenologische Relecture der Kategorienlehre in der Theologie Hermann Deusers - Wolfgang Achtner: Grundzüge einer evolutionären Theorie von Religion - Gesche Linde: Evolutionstheorie und Schöpfungsglaube. Doch kein »Abschied von der Kosmologie«? - Robert Cummings Neville: Hermann Deuser as an American Theologian

\section{Religion}

Michael Moxter: Subjektives Zeitbewusstsein und Synechismus - Saskia Wendel: Glaube - Handeln - Habitus - Matthias Jung: Weltanschauung als hermeneutischer Horizont der Religionsphilosophie - Hans Joas: Religiöse Erfahrung und ihre Interpretation. Reflexionen zu William James und Josiah Royce - Heiko Schulz: Die universalistische Religionsphilosophie Hermann Deusers. Ein dichterischer Versuch

\section{Wissenschaft}

Knut Wenzel: Die Interpretation der Offenbarung als Auslegung des Subjekts. Theologische Hermeneutik zwischen Verbindlichkeit und Unbedingtheit - Hans-Günter Heimbrock: Theologie: Lebensbezüge denken. Eine Miniatur in dialogischer Absicht - Eilert Herms: Der Horizont der Hirnforschung. Wie weit reicht der Beitrag der Hirnforschung zur Erfassung unserer Lebenswirklichkeit? - Dietmar Mieth: Leben und Leben oder: Lebensführung und Lebensforschung. Folgerungen für eine 'neue' Metaphysik im Sinne Hermann Deusers. Ein Essay - Ingolf U. Dalferth: Gibt es eine wissenschaftliche Rede von Gott?

IV. Kommentierung und Replik

Hermann Deuser: Nachwort: Kommentierung und Replik

Markus Kleinert Geboren 1974; Studium der Germanistik und Philosophie; 2003 Promotion; 2003-08 Assistent für Philosophie/Kunsttheorie an der Akademie der Bildenden Künste München; seit 2008 wissenschaftlicher Mitarbeiter am MaxWeber-Kolleg der Universität Erfurt (Leitung der Kierkegaard-Forschungsstelle).

Heiko Schulz Geboren 1959; Studium der Philosophie, Ev. Theologie und Erziehungswissenschaften; 1993 Promotion; 1999 Habilitation; 2002 Professor für Systematische Theologie an der Universität Duisburg-Essen/Campus Essen; seit 2009 Professor für Systematische Theologie und Religionsphilosophie an der Goethe-Universität Frankfurt a.M.

Jetzt bestellen:

https://mohrsiebeck.com/buch/natur-religion-wissenschaft-9783161550133?no_cache=1

order@mohrsiebeck.com

Telefon: +49 (0)7071-923-17

Telefax: +49(0)7071-51104 